\title{
The significance of preoperative estimated glomerular filtration rate on survival outcomes in patients who underwent radical cystectomy and non-continent urinary diversion
}

Ertugrul Sefik ${ }^{1}$, Serdar Celik ${ }^{1}$, Bulent Gunlusoy ${ }^{1}$, Ismail Basmaci ${ }^{1}$, Ibrahim H. Bozkurt ${ }^{1}$, Tansu Degirmenci ${ }^{1}$

${ }^{1}$ Department of Urology, Bozyaka Training and Research Hospital, Izmir, Turkey

\section{ABSTRACT}

Purpose: To evaluate the influence of preoperative renal function on survival outcomes in patients who underwent radical cystectomy (RC) with non-continent urinary diversion (UD). Materials and Methods: A total of 132 patients with bladder cancer who underwent RC with non-continent UD due to urothelial carcinoma from January 2006 toMarch 2017 at our tertiary referral center were retrospectively evaluated. Patients were divided into 2 groups as those with estimated glomerular filtration rate (eGFR) $<60 \mathrm{~mL} /$ $\mathrm{min} / 1.73 \mathrm{~m} 2$ and $\geq 60 \mathrm{~mL} / \mathrm{min} / 1.73 \mathrm{~m} 2$ according to preoperative eGFR levels. Patients' characteristics, preoperative clinical data, operative data, pathologic data, oncologic data and complications were compared between the groups.

Results: The mean age was $64.5 \pm 8.7$ (range: 32 - 83) years and the median followup was $30.9 \pm 31.7$ (range: $1-113$ ) months. There were 46 patients in Group 1 and 86 patients in Group 2. There was no difference in cancer-specific mortality (45.6\% for group 1 and 30.2\% for group 2, p=0.078) and survival (56.8 \pm 8.3 months for group 1 and $70.5 \pm 5.9$ months for group $2, p=0.087$ ) between the groups. Overall mortality was higher (63\% for group 1 and $40.7 \%$ for group $2, \mathrm{p}=0.014$ ) and overall survival $(43.6 \pm 6.9$ months for group 1 and $62.2 \pm 5.8$ months for group $2, p=0.03)$ was lower in Group 1 compared to Group 2.

Conclusions: Overall mortality was higher and overall survival was lower in patients with preoperative eGFR $<60 \mathrm{~mL} / \mathrm{s}$. More patients had preoperative hydronephrosis with $\mathrm{eGFR}<60 \mathrm{~mL} / \mathrm{s}$.

\section{ARTICLE INFO}

Ertugrul Sefik

http://orcid.org/0000-0002-7514-7133

\section{Keywords:}

Urinary Bladder Neoplasms;

Cystectomy; Urinary Diversion

Int Braz J Urol. 2020; 46: 566-74

Submitted for publication:

March 26, 2019

Accepted after revision:

October 13, 2019

Published as Ahead of Print:

March 25, 2020

\section{INTRODUCTION}

Radical cystectomy (RC) with extended pelvic lymph node dissection is the best choice of treatment in patients with non-metastatic muscle-invasive and high-risk non-muscle in- vasive bladder cancer (1-4). The procedure is completed with urinary diversion (UD) after the removal of the bladder. RC with UD is a 2-step, complex surgical procedure and is associated with significant risks of perioperative and long-term morbidity and mortality, including 
renal function deterioration and development of chronic renal disease (CKD) $(5,6)$.

The etiology of a renal function decrease after RC is likely multifactorial, including age-related changes, potential nephrotoxic chemotherapy, and the impact of patient comorbidities, which are frequent in such a population, and postoperative urinary tract obstruction and infection-related complications (7). Renal dysfunction is fairly common in this group of patients. Patients with bladder cancer largely comprise middle aged and elderly people (8). This is indicative of the presence of many morbidities that accompany bladder cancer in patients. Hamano et al. found that advanced preoperative CKD stage was significantly associated with poor oncological outcomes of bladder cancer after RC (8).

Comorbidities such as hypertension (HT), diabetes mellitus (DM) and vascular disease are important risk factors for the development of CKD at advanced age (9). Matsumoto et al. discussed the precise biological mechanism of association between tumor aggressiveness and CKD status with possible explanations. They found chronic inflammation induced by continuous exposure to oxidative stress and accompanying immune deficiency to be responsible mechanisms for CKD (10).

An important point in the evaluation of renal dysfunction is the method of choice to calculate the renal function. Most studies evaluate renal function variations using serum $\Delta$ creatinine as a surrogate value for the estimated glomerular filtration rate (eGFR) (11). Makino et al. assessed eGFR alterations over the years and risk factors for decreasing eGFR. Deterioration in renal function in early and late postoperative years was defined as a $\geq 25 \%$ decrease in the eGFR from preoperative to postoperative year one and a reduction in the eGFR of $>1 \mathrm{~mL} /$ $\mathrm{min} / 1.73 \mathrm{~m} 2$ annually in subsequent years (12).

In this study, we aimed to evaluate the influence of preoperative renal function on oncological outcomes and prognosis in patients who underwent RC and non-continent UD.

\section{MATERIALS AND METHODS}

A total of 132 patients with bladder cancer who underwent RC with non-continent UD due to urothelial carcinoma from January 2006 to March 2017 at our tertiary referral center were retrospectively evaluated. Patients were divided into 2 groups as eGFR $<60 \mathrm{~mL} / \mathrm{s}$ and $\geq 60 \mathrm{~mL} / \mathrm{s}$ according to preoperative eGFR levels. Patients without urothelial carcinoma on pathological examination, presence of upper tract urothelial carcinoma or obstructive stones and patients with incomplete medical records were excluded from the study. Patient characteristics, preoperative, operative and follow-up data were reviewed. The indications for $\mathrm{RC}$ were tumor invasion into the muscularis propria or prostatic stroma, or non-muscle-invasive disease (Ta, T1, or carcinoma in situ) refractory to transurethral resection with intravesical therapy.

Patient's characteristics (age, gender, presence of DM, HT and other comorbidities), preoperative clinical data (preoperative and postoperative at 3 months and creatinine and eGFR levels, American Society of Anesthesiologists (ASA) score, Eastern Cooperative Oncology Group (ECOG) performance score, Charlson comorbidity index and hydronephrosis presence, grade and laterality), operative data (operation time and diversion type data), pathologic data (preoperative T stage, tumor grade and carcinoma in situ (CIS) presence, postoperative $\mathrm{T}$ stage and tumor grade, surgical margin positivity, number of dissected lymph nodes, positive lymph node ratio, lymph node metastasis and percentage of positive lymph node data), oncologic data (upstaging, adjuvant chemotherapy, overall mortality (OM) and overall survival (OS), cancer specific mortality (CSM) and CSS and complications (hospitalization time, early medical complication, early surgical complications, complication data of Clavien-Dindo classification) were evaluated.

Type of incontinent urinary diversions were ureterocutaneostomy and incontinent ileal conduit. Creatinine was defined as difference between postoperative $3 \mathrm{rd}$ month creatinine and preoperative creatinine. Hydronephrosis was defined by anteroposterior diameter of the renal pelvis $>10 \mathrm{~mm}$ which was diagnosed by renal ultrasound or CT scan with or without secondary changes of renal parenchyma or renal function. 


\section{Statistical analysis}

Data were analyzed using the Statistical Package for Social Sciences, version 20.0 (SPSS, Chicago, Ill) software program. According to preoperative eGFR levels, patients were divided into two groups as preoperative eGFR $<60 \mathrm{~mL} / \mathrm{s}$ (Group 1) and preoperative eGFR $\geq 60 \mathrm{~mL} / \mathrm{s}$ (Group 2) groups. Mann-Whitney U test and Pearson Chi-square test analyses for univariate analysis and binary logistic regression analysis for multivariate analysis were used between the groups. In addition, Kaplan-Maier survival analysis and the log-rank test were used for OS and CSS times between groups. In addition, same tests were used for univariate and multivariate analysis of the factors affecting on overall and cancer specific deaths. A Cox regression model was created for evaluating the predictive factors on overall survivals. Data are given as mean \pm SD. However, results of analysis are given as median data. Statistical significance was defined as $\mathrm{p}<0.05$.

\section{RESULTS}

\section{Patients characteristics}

The mean age was $64.5 \pm 8.7$ (range: 32 83) years and the median follow-up time was 30.9 \pm 31.7 (range: 1-113) months. Consistent with previous data, there was a limited number of female patients (12 of $132,9 \%$ ). Mean OS and CSS of all patients were $56.3 \pm 4.7$ and $67.1 \pm 5$ months, respectively. There were 46 patients in Group 1 and 86 patients in Group 2. Comparison of patient's characteristics and preoperative clinical data between Group 1 and Group 2 according to preoperative eGFR levels were given in Table-1. In univariate analysis, the distributions of HT, DM, comorbidity data, ASA score, ECOG performance score and Charlson comorbidity index were similar, only preoperative hydronephrosis presence and hydronephrosis laterality were found to be significantly higher in Group 1 compared to Group 2. Preoperative and postoperative creatinine and eGFR at the third month and creatinine levels of the groups are given in Table- 1 to show mean creatinine and eGFR data. When we evaluated the peroperative and postoperative results and pathologic data between the groups, any prognostic and pathologic data were significant.

\section{Oncological outcomes}

Mean OS and CSS of all patients were $56.3 \pm 4.7$ and $67.1 \pm 5$ months, respectively. Overall and cancer specific deaths were 64 and 47 in all patients. In the comparison of oncological outcomes, although there was no difference in cancer specific mortality (45.6\% for group 1 and 30.2\% for group 2, $\mathrm{p}=0.078$ ) and CSS (56.8 \pm 8.3 months for group 1 and $70.5 \pm 5.9$ months for group $2, \mathrm{p}=0.087$ ) between the groups, OM was higher (63\% for group 1 and 40.7\% for group 2, $\mathrm{p}=0.014$ ) and OS (43.6 \pm 6.9 months for group 1 and $62.2 \pm 5.8$ months for group 2, $\mathrm{p}=0.03$ ) was lower in Group 1 compared to Group 2. Survival plots are given in Figure-1. Furthermore, upstaging and adjuvant chemotherapy rates were similar between the groups. Oncological data and survival findings are given in Table- 2 and Table-3. Also, univariate and multivariate analysis results of the factors affecting on overall and cancer specific deaths are given in Table-4. Preoperative eGFR was significantly associated with overall death. In addition, preoperative eGFR ( $\mathrm{p}=0.041, \mathrm{OR}: 0.514, \mathrm{CI}: 1.022-$ 2.738), preoperative hydronephrosis $(\mathrm{p}=0.002$, OR:0.878, CI:0.240-0.721), age ( $\mathrm{p}=0.038$, OR:0.03, CI:1.002-1.061) and pathological T stage $(\mathrm{p}=0.013$, OR:0.349, CI:0.136-0.619) were found to be associated with overall survival after radical cystectomy in Cox regression model $(p=0.001)$. In groups, hospitalization time, early medical and surgical complication rates, and complication rates according to Clavien-Dindo classification were also similar.

\section{DISCUSSION}

There is ongoing debate about the effect of preoperative patient status on the surgical outcomes after radical cystectomy. CKD, HT, DM and vascular diseases are well-known risk factors which have negative impact on surgical outcomes. An independent, graded association was observed between reduced eGFR and the risk of death, in a large, community-based population. These findings highlight the clinical and public health 
Table 1 - Comparison of patient's characteristics and preoperative findings between eGFR $<60 \mathrm{~mL} / \mathrm{min} / 1.73 \mathrm{~m} 2$ and eGFR $\geq 60 \mathrm{~mL} / \mathrm{min} / 1.73 \mathrm{~m} 2$ groups according to preoperative eGFR levels.

\begin{tabular}{|c|c|c|c|c|}
\hline & & $\begin{array}{c}\text { Preoperative eGFR } \\
<60 \mathrm{~mL} / \mathrm{min} / 1.73 \mathrm{~m} 2 \\
(\mathrm{n}=46)\end{array}$ & $\begin{array}{c}\text { Preoperative eGFR } \\
\geq 60 \mathrm{~mL} / \mathrm{min} / 1.73 \mathrm{~m} 2 \\
(\mathrm{n}=86)\end{array}$ & $p$ \\
\hline \multicolumn{2}{|l|}{ Age (years) $\left(\right.$ mean $\left._{ \pm} S D\right)$} & $65.9 \pm 9.5$ & $63.7 \pm 8.2$ & 0.145 \\
\hline \multirow[t]{2}{*}{ Gender } & Female & 7 & 5 & 0.073 \\
\hline & Male & 39 & 81 & \\
\hline \multicolumn{2}{|c|}{ Preoperative creatinine $\left(\right.$ mean $\left._{ \pm} \mathrm{SD}\right)$} & $1.69 \pm 0.57$ & $0.96 \pm 0.15$ & - \\
\hline \multicolumn{2}{|l|}{ Preoperative eGFR (mean $\pm S D)$} & $41.6 \pm 13$ & $80 \pm 16.9$ & - \\
\hline \multicolumn{2}{|c|}{ Postoperative 3 month creatinine $\left(\right.$ mean $_{ \pm} \mathrm{SD}$ ) } & $1.72 \pm 0.66$ & $1.21 \pm 0.57$ & $<0.001$ \\
\hline \multicolumn{2}{|c|}{ Postoperative 3 month eGFR (mean \pm SD) } & $45 \pm 18.4$ & $69.9 \pm 22.9$ & $<0.001$ \\
\hline \multicolumn{2}{|l|}{$\Delta$ creatinine $\left(\right.$ mean $\left._{ \pm} \mathrm{SD}\right)$} & $0.04 \pm 0.66$ & $0.26 \pm 0.55$ & 0.015 \\
\hline \multirow[t]{4}{*}{ ASA } & 1 & 1 & 4 & 0.218 \\
\hline & 2 & 3 & 46 & \\
\hline & 3 & 12 & 34 & \\
\hline & 4 & 0 & 2 & \\
\hline \multirow[t]{5}{*}{ ECOG Performance score } & 0 & 8 & 25 & 0.364 \\
\hline & 1 & 24 & 36 & \\
\hline & 2 & 9 & 16 & \\
\hline & 3 & 3 & 7 & \\
\hline & 4 & 1 & 0 & \\
\hline \multirow[t]{4}{*}{ Charlson comorbidity index } & 0 & 0 & 1 & 0.295 \\
\hline & 1 & 1 & 2 & \\
\hline & 2 & 13 & 13 & \\
\hline & $3+$ & 32 & 70 & \\
\hline \multicolumn{2}{|l|}{$\mathrm{DM}, \mathrm{n}(\%)$} & $10(21.7)$ & $15(17.4)$ & 0.548 \\
\hline \multicolumn{2}{|l|}{ HT, n (\%) } & $24(52.2)$ & $30(34.9)$ & 0.054 \\
\hline \multicolumn{2}{|l|}{ Any comorbidity, n (\%) } & $37(80.4)$ & $60(69.8)$ & 0.186 \\
\hline \multirow{2}{*}{$\begin{array}{l}\text { Preoperative } \\
\text { hydronephrosis }\end{array}$} & positive & 30 & 23 & $<0.001$ \\
\hline & negative & 16 & 63 & ${ }^{*}<0.001$ \\
\hline \multirow[t]{2}{*}{ Hydronephrosis laterality } & unilateral & 18 & 21 & 0.01 \\
\hline & bilateral & 12 & 2 & *0.019 \\
\hline \multirow{4}{*}{$\begin{array}{l}\text { Preoperative hydrophrosis } \\
\text { grade }\end{array}$} & 1 & 1 & 4 & 0.276 \\
\hline & 2 & 9 & 4 & \\
\hline & 3 & 15 & 10 & \\
\hline & 4 & 5 & 5 & \\
\hline \multicolumn{2}{|c|}{ Preoperative nephrostomy tube insertion for grade 3-4 hydrophrosis } & $12(60)$ & $7(46.7)$ & 0.767 \\
\hline
\end{tabular}

Mann Whitney U test and Pearson Chi-square test.

${ }^{*}$ Binary logistic regression analysis for significant data of univariate analysis results.

$\mathbf{A S A}=$ American Society of Anesthesiologists; $\mathbf{E C O G}=$ Eastern Cooperative Oncology Group; $\mathbf{D M}=$ Diabetes mellitus; $\mathbf{H T}=$ Hypertension 
Figure 1 - A) Overall survival plots of Kaplan-Maier analysis. B) Cancer specific survival plots of Kaplan-Maier analysis.
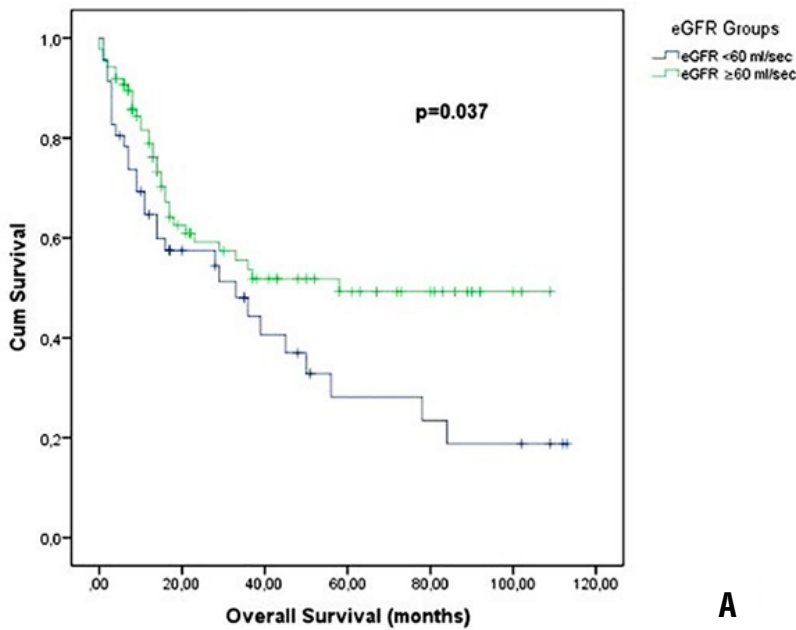

importance of chronic renal insufficiency (13). Interest in the influence of preoperative renal insufficiency on cancer prognosis has increased because of its prevalence in elderly patients with muscle-invasive bladder cancer (3). Eisenberg et al. reported that decreased renal function is noted in most patients during long-term follow-up after radical cystectomy and approximately $70 \%$ of patients undergoing RC with UD experience eGFR decline postoperatively. They also stated that choice of urinary diversion was not independently associated with decreased renal function (7).

Despite the variety of diversion techniques, either continent or non-continent, patients undergoing RC have a life-long risk of CKD (11). Continent diversion methods are mostly not preferred in the case of preoperative CKD, while de Toledo et al. emphasized that gastric neobladder can be used in highly selected cases (e.g., renal insufficiency) because of its high morbidity and mortality rates (14). According to the selected diversion method, our study group consisted of patients with non-continent diversion. There were 77 patients with ileal conduit diversion (ICD) and 55 patients with ureterocutaneostomy (UC). Our patients were divided into 2 groups to compare the effect of preoperative eGFR on oncologic results. In patients with preoperative eGFR

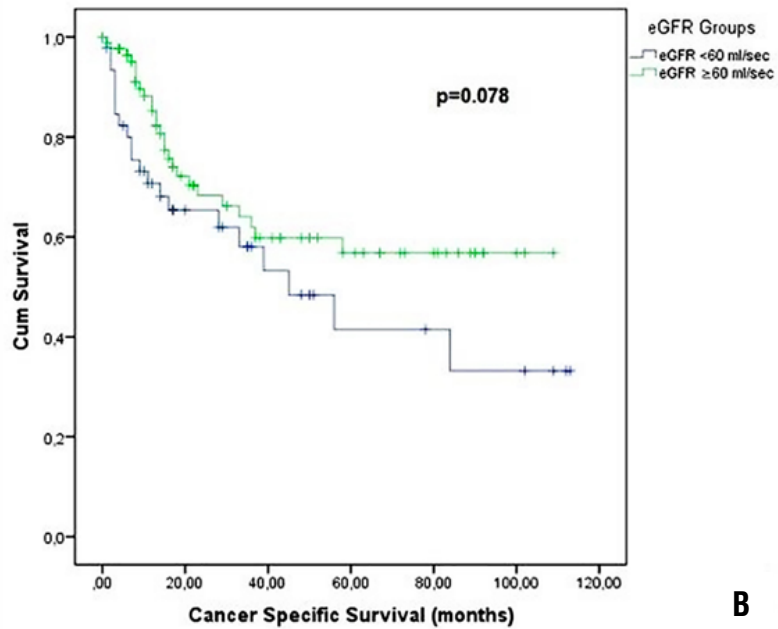

$<60 \mathrm{~mL} / \mathrm{s}$, preoperative creatinine level increased from $1.69 \pm 0.57$ to $1.72 \pm 0.66$. However, creatinine levels were worse in patients with preoperative eGFR $\geq 60 \mathrm{~mL} / \mathrm{s}$ (increased from $0.96 \pm 0.15$ to $1.21 \pm 0.579$ ). This situation can be explained as relative improvement due to the regression of preoperative hydronephrosis in patients with preoperative eGFR $<60 \mathrm{~mL} / \mathrm{s}$. In the comparison of groups, more patients already had preoperative hydronephrosis in Group 1. Urinary tract obstruction was the leading cause of long-term renal function impairment, regardless of whether the patient had ileal conduit diversion or orthotopic ileal bladder substitution. Also, Eisenberg et al. reported that age, preoperative kidney function and chronic hypertension, and the postoperative complications of hydronephrosis, pyelonephritis and uretero-enteric anastomotic stricture were associated with an increased risk of decreased renal function (7). Our findings support the effect of preoperative hydronephrosis on renal functions and oncologic outcomes.

In recent years, population-based studies reported a slow increase in cancer risk as CKD status progressed $(15,16)$. In a previous study, it was found that patients with CKD had worse prognosis, higher tumor recurrence and progression rates in primary non-muscle invasive bladder cancer (17). In some other stu- 
Table 2 - Comparison of operative and pathologic data between Group 1 and Group 2.

\begin{tabular}{|c|c|c|c|c|}
\hline & & $\begin{array}{l}\text { Preoperative eGFR } \\
<60 \mathrm{~mL} / \mathrm{min} / 1.73 \mathrm{~m} 2 \\
(\mathrm{n}=46)\end{array}$ & $\begin{array}{c}\text { Preoperative eGFR } \\
\geq 60 \mathrm{~mL} / \mathrm{min} / 1.73 \mathrm{~m} 2 \\
(\mathrm{n}=86)\end{array}$ & $P^{*}$ \\
\hline \multirow[t]{3}{*}{ Preoperative T stage } & $\leq \mathrm{T} 1$ & 6 & 9 & 0.721 \\
\hline & T2 & 38 & 75 & \\
\hline & T3 & 2 & 2 & \\
\hline \multirow{3}{*}{$\begin{array}{l}\text { Preoperative tumor } \\
\text { grade }\end{array}$} & Grade1 & 1 & 2 & 0.485 \\
\hline & Grade2 & 3 & 2 & \\
\hline & Grade3 & 42 & 82 & \\
\hline \multirow[t]{2}{*}{ CIS } & positive & 10 & 30 & 0.108 \\
\hline & negative & 36 & 55 & \\
\hline Operation time (hours) & & $5.6 \pm 1.3$ & $5.8 \pm 1.1$ & 0.369 \\
\hline \multirow[t]{4}{*}{ Postoperative T stage } & $\mathrm{T} 1$ & 8 & 20 & 0.364 \\
\hline & $\mathrm{T} 2$ & 17 & 39 & \\
\hline & T3 & 8 & 13 & \\
\hline & $\mathrm{T} 4$ & 13 & 14 & \\
\hline \multirow{3}{*}{$\begin{array}{l}\text { Postoperative tumor } \\
\text { Grade }\end{array}$} & 1 & 3 & 5 & 0.905 \\
\hline & 2 & 1 & 3 & \\
\hline & 3 & 37 & 68 & \\
\hline \multirow{2}{*}{$\begin{array}{l}\text { Surgical margin } \\
\text { positivity }\end{array}$} & positive & 13 & 13 & 0.07 \\
\hline & negative & 33 & 73 & \\
\hline \multicolumn{2}{|c|}{ Number of dissected lymph node } & $12.4 \pm 5.9$ & $13.2 \pm 4.9$ & 0.430 \\
\hline \multicolumn{2}{|l|}{ Positive lymph node ratio } & $1.1 \pm 2.4$ & $0.4 \pm 1.2$ & 0.121 \\
\hline \multirow[t]{2}{*}{ Lymph node metastasis } & Positive & 11 & 14 & 0.318 \\
\hline & Negative & 34 & 68 & \\
\hline \multicolumn{2}{|c|}{ Percentage of positive lymph node } & $8.9 \pm 19.1$ & $3.5 \pm 9.4$ & 0.136 \\
\hline \multirow[t]{2}{*}{ Diversion type } & Ureterocutaneostomy & 23 & 32 & 0.156 \\
\hline & Ileal conduit & 23 & 54 & \\
\hline
\end{tabular}

*Mann Whitney U test and Pearson Chi-square test

CIS $=$ Carcinoma In Situ

dies, it was shown that poor oncologic results accompany CKD in muscle-invasive bladder cancer patients who underwent $\mathrm{RC}(18,19)$. There is an age-dependent physiological decrease in eGFR, which was defined as a $>10 \mathrm{~mL} /$ $\mathrm{min} / 1.73 \mathrm{~m} 2$ drop in eGFR from baseline, which occurs per decade (20). In the current study, overall mortality and survival were significantly worse with preoperative eGFR $<60 \mathrm{~mL} / \mathrm{s}$.
CKD might not only limit long-term outcomes by increasing the risk of cardiovascular morbidity and mortality, but also compromise short-term outcomes (13).

Long-term renal function after RC can be adversely affected by several factors, including age, potential nephrotoxic chemotherapy, comorbidities, and diversion-related factors (11). Physicians dealing with uro-oncology 
mostly prefer non-continent diversion techniques instead of orthotopic neo-bladder formation in patients with concomitant morbidities such as CKD, cardiovascular or advanced chronic obstructive lung disease.

We showed that overall survival and mortality were poorly affected by low eGFR in patients undergoing non-continent diversion. Our study was limited by its retrospective design and small number of patients. Also, the threshold value to define renal failure is heterogeneous in different studies. Blood urea and creatinine estimations are easy and inexpensive, but these biochemical parameters can

Table 3 - Comparison of postoperative data, complications and survival findings between Group 1 and Group 2.

\begin{tabular}{|c|c|c|c|c|}
\hline & & $\begin{array}{c}\text { Preoperative eGFR <60mL/ } \\
\min / 1.73 \mathrm{~m} 2(\mathrm{n}=46)\end{array}$ & $\begin{array}{l}\text { Preoperative eGFR } \\
\geq 60 \mathrm{~mL} / \mathrm{min} / 1.73 \mathrm{~m} 2 \\
(\mathrm{n}=86)\end{array}$ & $p$ \\
\hline \multirow{2}{*}{ Upstaging } & Positive & 22 & 55 & \multirow{2}{*}{0.073} \\
\hline & Negative & 24 & 31 & \\
\hline \multirow{3}{*}{ Upstaging } & upstaging & 24 & 31 & \multirow{3}{*}{0.160} \\
\hline & downstaging & 5 & 17 & \\
\hline & No differance & 17 & 38 & \\
\hline Adjuvant chemotherapy, n (\%) & & $12(26.1)$ & $22(25.6)$ & 0.950 \\
\hline \multirow{2}{*}{ Overall Mortality, n (\%) } & & $29(63)$ & $35(40.7)$ & 0.014 \\
\hline & & & & ${ }^{*} 0.015$ \\
\hline Overall Survival & & $43.6 \pm 6.9$ & $62.2 \pm 5.8$ & $\# 0.037$ \\
\hline Cancer Specific Mortality, n (\%) & & $21(45.6)$ & $26(30.2)$ & 0.078 \\
\hline Cancer Specific Survival & & $56.8 \pm 8.3$ & $70.5 \pm 5.9$ & $\# 0.087$ \\
\hline Surgery time (hours) & & $5.6 \pm 1.3$ & $5.8 \pm 1.1$ & 0.518 \\
\hline Hospitalization time & & $11.3 \pm 4.6$ & $12.1 \pm 6.3$ & 0.475 \\
\hline \multirow{2}{*}{$\begin{array}{l}\text { Early medical } \\
\text { complication }\end{array}$} & Positive & 14 & 20 & 0.369 \\
\hline & Negative & 31 & 66 & \multirow{3}{*}{0.095} \\
\hline \multirow{2}{*}{$\begin{array}{l}\text { Early surgical } \\
\text { complication }\end{array}$} & Positive & 15 & 41 & \\
\hline & Negative & 31 & 45 & \\
\hline \multirow{6}{*}{ Clavien-Dindo } & 1 & 5 & 8 & \multirow{6}{*}{0.357} \\
\hline & 2 & 34 & 51 & \\
\hline & 3a & 1 & 2 & \\
\hline & $3 b$ & 3 & 15 & \\
\hline & $4 a$ & 1 & 7 & \\
\hline & 5 & 2 & 3 & \\
\hline
\end{tabular}

Mann Whitney U test and Pearson Chi-square test

${ }^{*}$ Binary logistic regression analysis for significant data of univariate analysis results

\# Kaplan-Maier survival analysis and the log-rank test 
Table 4 - Univariate and multivariate analysis of the factors affecting on overall and cancer specific death.

\begin{tabular}{|c|c|c|c|c|c|c|c|}
\hline & & \multicolumn{3}{|c|}{ Overall death } & \multicolumn{3}{|c|}{ Cancer specific death } \\
\hline & & $n=64$ & $p$ & $p^{*}$ & $\mathrm{n}=47$ & $p$ & $p^{*}$ \\
\hline \multirow{2}{*}{$\begin{array}{l}\text { Preoperative } \\
\text { hydronephrosis }\end{array}$} & Positive & 35 & 0.001 & 0.071 & 27 & 0.002 & 0.052 \\
\hline & Negative & 29 & & & 20 & & \\
\hline \multirow[t]{3}{*}{ Preoperative T stage } & $\leq \mathrm{T} 1$ & 8 & 0.501 & - & 5 & 0.247 & - \\
\hline & T2 & 53 & & & 39 & & \\
\hline & T3 & 3 & & & 3 & & \\
\hline \multirow[t]{2}{*}{ eGFR (mL/sec) } & $<60$ & 29 & 0.014 & $p=0.040$ & 21 & 0.078 & - \\
\hline & $\geq 60$ & 35 & & $\begin{array}{c}\text { HR:2.33 } \\
\text { (Cl:1.04-5.22) }\end{array}$ & 26 & & \\
\hline \multirow[t]{4}{*}{ Postoperative T stage } & $\mathrm{T} 1$ & 10 & $<0.001$ & 0.118 & 6 & $<0.001$ & 0.614 \\
\hline & T2 & 19 & & & 13 & & \\
\hline & T3 & 13 & & & 10 & & \\
\hline & $\mathrm{T} 4$ & 22 & & & 18 & & \\
\hline \multirow{3}{*}{$\begin{array}{l}\text { Postoperative tumor } \\
\text { Grade }\end{array}$} & 1 & 4 & 0.988 & - & 3 & 0.890 & - \\
\hline & 2 & 2 & & & 2 & & \\
\hline & 3 & 55 & & & 40 & & \\
\hline \multirow{2}{*}{$\begin{array}{l}\text { Surgical margin } \\
\text { positivity }\end{array}$} & Positive & 22 & $<0.001$ & 0.087 & 19 & $<0.001$ & 0.109 \\
\hline & Negative & 42 & & & 28 & & \\
\hline \multirow[t]{2}{*}{ Lymph node metastasis } & Positive & 17 & 0.016 & 0.284 & 15 & 0.003 & 0.076 \\
\hline & Negative & 42 & & & 28 & & \\
\hline \multirow[t]{2}{*}{ Upstaging } & Positive & 36 & 0.001 & 0.544 & 29 & 0.001 & 0.467 \\
\hline & Negative & 28 & & & 18 & & \\
\hline
\end{tabular}

${ }^{*}$ Multivariate analysis results

be affected by different metabolic events. In fact, each diversion method leads to subtle metabolic changes causing confused results. As far as finding the ideal method, eGFR seems to give best results for the measurement of renal failure.

\section{CONCLUSIONS}

Preoperative hydronephrosis, which is a well-known prognostic factor in patients undergoing radical cystectomy, was significantly higher in patients with eGFR $<60 \mathrm{~mL} / \mathrm{s}$. Overall mortality was higher and overall survival was lower in patients with preoperative eGFR $<60 \mathrm{~mL} / \mathrm{s}$. Renal dysfunction is an important risk factor for overall survival in patients who undergo radical cystectomy.

\section{CONFLICT OF INTEREST}

None declared. 


\section{REFERENCES}

1. Studer UE, Burkhard FC, Schumacher M, Kessler TM, Thoeny $\mathrm{H}$, Fleischmann A, et al. Twenty years experience with an ileal orthotopic low pressure bladder substitute--lessons to be learned. J Urol. 2006;176:161-6.

2. World Health Organization (WHO) Consensus Conference on Bladder Cancer, Hautmann RE, Abol-Enein H, Hafez K, Haro I, Mansson W, Mills RD, et al. Urinary diversion. Urology. 2007;69(1 Suppl):17-49.

3. Stein JP, Lieskovsky G, Cote R, Groshen S, Feng AC, Boyd S, et al. Radical cystectomy in the treatment of invasive bladder cancer: long-term results in 1,054 patients. J Clin Oncol. 2001;19:666-75.

4. Corradi RB, Galvao GJ, Oliveira GM, Carneiro VF, Miconi WG, Salles PG, et al. Radical cystectomy with pelvic lymphadenectomy: pathologic, operative and morbidity outcomes in a Brazilian cohort. Int Braz J Urol. 2016;42:431-7.

5. Shabsigh A, Korets R, Vora KC, Brooks CM, Cronin AM, Savage C, et al. Defining early morbidity of radical cystectomy for patients with bladder cancer using a standardized reporting methodology. Eur Urol. 2009;55:164-74.

6. Shimko MS, Tollefson MK, Umbreit EC, Farmer SA, Blute $\mathrm{ML}$, Frank I. Long-term complications of conduit urinary diversion. J Urol. 2011;185:562-7.

7. Eisenberg MS, Thompson RH, Frank I, Kim SP, Cotter KJ, Tollefson MK, et al. Long-term renal function outcomes after radical cystectomy. J Urol. 2014;191:619-25.

8. Hamano I, Hatakeyama S, Iwamurau H, Fujita N, Fukushi K, Narita T, et al. Preoperative chronic kidney disease predicts poor oncological outcomes after radical cystectomy in patients with muscle-invasive bladder cancer. Oncotarget. 2017:8:61404-61414.

9. Jin $X D$, Roethlisberger $S$, Burkhard FC, Birkhaeuser $F$, Thoeny HC, Studer UE. Long-term renal function after urinary diversion by ileal conduit or orthotopic ileal bladder substitution. Eur Urol. 2012;61:491-7.

10. Matsumoto A, Nakagawa T, Kanatani A, Ikeda M, Kawai T, Miyakawa J, et al. Preoperative chronic kidney disease is predictive of oncological outcome of radical cystectomy for bladder cancer. World J Urol. 2018;36:249-256.

11. Rouanne M, Perreaud A, Letang N, Yonneau L, Neuzillet $\mathrm{Y}$, Hervé JM, et al. Trends in renal function after radical cystectomy and ileal conduit diversion: new insights regarding estimated glomerular filtration rate variations. Clin Genitourin Cancer. 2015;13:e139-44.
12. Makino K, Nakagawa T, Kanatani A, Kawai T, Taguchi S, Otsuka M, et al. Biphasic decline in renal function after radical cystectomy with urinary diversion. Int J Clin Oncol. 2017;22:359-365.

13. Go AS, Chertow GM, Fan D, McCulloch CE, Hsu CY. Chronic kidney disease and the risks of death, cardiovascular events, and hospitalization. N Engl J Med. 2004;351:1296-305. Erratum in: N Engl J Med. 2008;18:4.

14. de Toledo AF, da Cunha CEB, Steppe CH, de Toledo DW, Noronha JAP, Carvalhal G. Gastric neobladders: surgical outcomes of 91 cases using different techniques. Int Braz $J$ Urol. 2018:44:914-919.

15. Weng PH, Hung KY, Huang HL, Chen JH, Sung PK, Huang KC. Cancer-specific mortality in chronic kidney disease: longitudinal follow-up of a large cohort. Clin J Am Soc Nephrol. 2011;6:1121-8.

16. Iff S, Craig JC, Turner R, Chapman JR, Wang JJ, Mitchell P, et al. Reduced estimated GFR and cancer mortality. Am J Kidney Dis. 2014;63:23-30.

17. Li CE, Chien CS, Chuang YC, Chang YI, Tang HP, Kang CH. Chronic kidney disease as an important risk factor for tumor recurrences, progression and overall survival in primary non-muscle-invasive bladder cancer. Int Urol Nephrol. 2016:48:993-9.

18. Thrasher JB, Frazier HA, Robertson JE, Dodge RK, Paulson DF. Clinical variables which serve as predictors of cancer-specific survival among patients treated with radical cystectomy for transitional cell carcinoma of the bladder and prostate. Cancer. 1994;73:1708-15.

19. Chahal R, Sundaram SK, Iddenden R, Forman DF, Weston PM, Harrison SC. A study of the morbidity, mortality and long-term survival following radical cystectomy and radical radiotherapy in the treatment of invasive bladder cancer in Yorkshire. Eur Urol. 2003;43:246-57.

20. Gershman B, Eisenberg MS, Thompson RH, Frank I, Kaushik D, Tarrell R, et al. Comparative impact of continent and incontinent urinary diversion on long-term renal function after radical cystectomy in patients with preoperative chronic kidney disease 2 and chronic kidney disease 3a. Int J Urol. 2015;22:651-6.

Correspondence address: Ertugrul Sefik, MD Department of Urology, Bozyaka Training and Research Hospital, Izmir, Turkey Telephone: + 90531 791-5285 E-mail: sefikanamur@yahoo.com 